\title{
Bronchial responsiveness, eosinophilia, and short term exposure to air pollution
}

\author{
Vidar Søyseth, Johny Kongerud, Peder Broen, Peer Lilleng, Jacob Boe
}

\begin{abstract}
The number of capillary blood eosinophils and the prevalence of bronchial hyperresponsiveness (BHR) were compared between schoolchildren living in a polluted area (Årdal) and unpolluted area (Læerdal).

In Ârdal there is an aluminium smelter emitting sulphur dioxide and fluoride to the environment. Daily measurements of these pollutants in ambient air were available. The mean number of eosinophils in Årdal was $220 \times 10^{6} / 1$ compared with $106 \times 10^{6} / 1$ in Lardal. The prevalence of BHR was $15.9 \%$ in Årdal and $11.8 \%$ in Lardal. The odds ratio of having BHR in relation to these pollutants during the last 24 hours were: 1.12 (95\% confidence interval (CI) 1.01 to 1.24 ) by increasing sulphur dioxide with $10 \mu \mathrm{g} / \mathrm{m}^{3}$, and 1.31 (95\% CI 1.07 to 1.60 ) when fluoride exposure increased with $1 \mu \mathrm{g} / \mathrm{m}^{3}$. Similarly, these exposures were associated with a decrease in eosinophils of $-21 \times 10^{6} / 1(95 \%$ CI -36 to $-6)$ and $-52 \times 10^{6} / 1(95 \%$ CI -98 to -8$)$, respectively, in atopics.

It is hypothesised that recent exposure to irritants induces changes in the airways leading to BHR in addition to recruitment of eosinophils to the airways in atopic subjects.

(Arch Dis Child 1995; 73: 418-422)
\end{abstract}

Keywords: air pollution, bronchial provocation tests, eosinophils, epidemiology.

Health Department, Hydro Aluminium Årdal and Department of Thoracic Medicine, Rikshospitalet, University of Oslo, Norway

V Søyseth

Department of Thoracic Medicine, Rikshospitalet, University of Oslo $\mathrm{J}$ Kongerud

J Boe

Årdal Primary Health Care Unit, Årdal Municipality $P$ Broen

Læerdal Primary Health Care Unit, Lardal Municipality P Lilleng

Correspondence to: Dr Vidar Søyseth, Medica Department, Lillehammer Hospital, N-2600 Lillehammer, Norway.

Accepted 3 July 1995
The number of blood eosinophils is increased in subjects who are atopic compared with those who are non-atopic. ${ }^{1}$ An accumulation of eosinophils is reported in the bronchoalveolar lavage fluid during allergen induced late phase reaction. ${ }^{2}$ This influx of eosinophils to the airways is associated with a temporal increase in bronchial responsiveness accompanied by a decrease in peripheral eosinophils. ${ }^{3}$ The number of eosinophils in bronchoalveolar fluid is also positively correlated with bronchial responsiveness in asthmatic adults and children. ${ }^{3} 4$

Results from experimental studies in guinea pigs have indicated that eosinophils accumulate in the lower airways after exposure to ozone $e^{5}$ and nitrogen dioxide. ${ }^{6}$ It is thus likely that nonimmunological agents can stimulate eosinophils. Studies in humans of the effect of different environmental exposures on the number of blood eosinophils are recommended. ${ }^{7}$

We counted capillary blood eosinophils and measured bronchial responsiveness to methacholine in schoolchildren in two valleys in western Norway (Årdal and Lærdal). In Årdal (index area) there is an aluminium plant emitting air pollutants to the environment, whereas Lærdal (reference area) is an agricultural municipality with a low level of air pollution. In a previous report of the same cohort of schoolchildren we found that the prevalence of bronchial hyperresponsiveness (BHR) was positively associated with exposure to air pollutants during the first three years of life. ${ }^{8}$

The objective of the present study was to investigate the effect of recent (during the last 24 hours to 30 days) exposure to sulphur dioxide and fluoride on blood eosinophils and bronchial responsiveness.

\section{Subjects and methods}

STUDY AREA

Both Årdal and Lærdal are valleys with mountains with an altitude of $1200-1500 \mathrm{~m}$ on each side. In Årdal, there are two towns separated by a $12 \mathrm{~km}$ long lake: Årdalstangen and Øvre Ardal. The size of the population in these two towns is about 2500 and 4000 respectively. The Lxrdal valley is about $40 \mathrm{~km}$ long and people live at points throughout the length of the valley. About $25 \%$ of the population are farmers and the total population is some 2300 people. In Lærdal, no industry emits air pollutants and the traffic is sparse. The climate is very similar in the two valleys: the annual rainfall ranges from 490 to $690 \mathrm{~mm}$ and the mean temperature is about $-3^{\circ} \mathrm{C}$ in January and $14^{\circ} \mathrm{C}$ in July.

STUDY POPULATION

All the pupils in the first, third, and fifth grades (that is, aged 7-13 years) in Årdal and Lærdal were invited to participate in a cross sectional study during the 1989-92 winter seasons. One of the parents attended the examination with the child. All the children and their parents were informed about the aims of the study and the test procedures. The protocol was approved by the regional ethics committee. In all, 620 from 645 eligible pupils attended the clinical examination, that is, the overall response rate was $96 \cdot 1 \%$. The mean (SD) age was $9.3(1 \cdot 7)$ years, $8.2 \%$ had ever had asthma, and a positive skin prick test was found in $17 \cdot 8 \%$.

\section{QUESTIONNAIRES}

Before the clinical examination, the parents received a respiratory questionnaire, ${ }^{9}$ including questions about the familial history of asthma or hay fever, respiratory symptoms, 
bronchitis before 2 years of age, and the parents' smoking habits at the time of the examination.

\section{BLOOD EOSINOPHIL CELL COUNT AND SKIN PRICK TEST}

Capillary blood smears were collected and eosinophils were counted using a FuchsRosenthal chamber. ${ }^{10}$ The result was given as the mean of two parallel counts, measured as $\times 10^{6}$ cells/1. Of the 620 subjects who participated in the study, a capillary blood sample was obtained from $434(70.0 \%)$ subjects.

Skin prick tests were performed on 556 $(89.7 \%)$ of the 620 subjects who attended the examination using lancets coated with eight common aeroallergens (Phazet, Pharmacia, Uppsala, Sweden). ${ }^{11}$ Five doctors were trained to perform the skin prick test; one of them (VS) tested subjects in both areas. The following allergens were used: birch, cat, cladosporium, dog, horse, house mite, mugwort and timothy, in addition to histamine and saline references. The weal size was recorded after 15 minutes and given as the mean of the long axis and its perpendicular and was regarded as positive if it was $\geqslant 3 \mathrm{~mm}$. Those who had a positive reaction to at least one of the skin prick tests were considered to have atopy.

\section{LUNG FUNCTION AND BRONCHIAL}

RESPONSIVENESS

Spirometry was performed using a pneumotachograph (Vitalograph, Birmingham) which was calibrated daily to 5 litres using a 1 litre syringe. The test was accepted if the difference between the best and the second best test varied by less than $5 \%$ or $100 \mathrm{ml}$, whichever was larger. The result was given as forced expiratory volume in one second $\left(\mathrm{FEV}_{1}\right)$ as a percentage of predicted using the predicted values published by Cotes. ${ }^{12}$ Methacholine challenge was performed using a shortened version of the protocol suggested by Cockcroft et al. ${ }^{1314}$ All the subjects whose baseline $\mathrm{FEV}_{1}$ was $\geqslant 70 \%$ of predicted $^{12}$ were invited to perform the challenge test. The response to the methacholine challenge was expressed as $\mathrm{PC}_{20}$ : that is, the concentration that caused a fall in $\mathrm{FEV}_{1}$ of $20 \%$ from baseline calculated by linear interpolation on the log linear dose response curve. If $\mathrm{FEV}_{1}$ was less than $70 \%$ of predicted, ${ }^{12}$ the subject was asked to perform a reversibility test. After two inhalations of $0.1 \mathrm{mg}$ of salbutamol a second spirometry measurement was made five minutes later. A subject was regarded as having $\mathrm{BHR}$ if $\mathrm{PC}_{20}$ $\leqslant 8 \mathrm{mg} / \mathrm{ml}$ or $\mathrm{FEV}_{1}$ increased by more than $10 \%$ at the reversibility test. Bronchial responsiveness was also expressed as the log transformed dose response slope as suggested by O'Connor et al. ${ }^{15}$

ASSESSMENT OF ENVIRONMENTAL EXPOSURE In Øvre Årdal there is an aluminium smelter producing 180000 tonnes of primary aluminium annually. The main emissions from the plant are sulphur dioxide, fluoride, and particulates. The concentration of sulphur dioxide and fluoride in ambient outdoor air has been measured every day at one station in both towns since 1978, using equipment for continuous sampling. Two types of sampler have been used: one equipped with an absorption solution for sulphur dioxide and one with an alkaline filter for the absorption of fluoride. Both kinds of samplers were constructed exclusively to absorb gas. The sampler shifted from one bottle (sulphur dioxide) and filter (fluoride) to the next every 24 hours at $10 \mathrm{am}$, that is, the daily mean was measured. The subjects attended the examination between 8 am and $3 \mathrm{pm}$. Hence, the measurements of sulphur dioxide and fluoride on the previous day could be regarded as estimates of the mean exposure to these agents during the last 24 hours. The majority of the population in Årdal live less than $2 \mathrm{~km}$ from the location of the samplers. Data on temperature and humidity were also available.

The exposure of the subjects was classified as follows. In each subject living in the index area two indices of exposure to sulphur dioxide and fluoride were used: (i) current exposure: exposure during the last 24 hours prior to the examination and (ii) last month exposure: exposure during 1-30 days before the survey. The median and 10th-90th centiles of the exposure to these agents are listed in table 1.

During the winter of 1991 , the concentration of sulphur dioxide in Lærdal was measured using the same type of equipment as in Årdal and analysed at the same laboratory. The median was $2 \cdot 5 \mu \mathrm{g} / \mathrm{m}^{3}$ (10th-90th centiles $0 \cdot 1-11 \cdot 1$ ) in 44 observations (that is, about $1 / 10$ of the level in Årdal). At the same time, the concentration of fluorides was not detectable.

\section{STATISTICAL ANALYSES}

Univariate analyses ( $t$ tests and $\chi^{2}$ statistics) were used to investigate the association between each of the outcomes and the exposure variables in the index group. The association between the outcome and each of the following covariates were examined: age, gender, atopy, familial history of asthma or hay fever, $\mathrm{FEV}_{1}$ (as \% of the predicted value), bronchitis before 2 years of age, temperature, humidity, parental smoking, and presence of animals in the household.

Multivariate analyses were used in order to control for extraneous effects. A covariate was included if the univariate test had a $\mathrm{p}$ value $\leqslant 0 \cdot 25 .{ }^{16}$ The full model was reduced by backward elimination using the partial $\mathrm{F}$ test as the selection criterion ${ }^{17}$ in the multiple regression model and the log likelihood test in the logistic

Table 1 Median exposure $\left(\mu g / \mathrm{m}^{3}\right)$ to sulphur dioxide and fluoride in the index group (10th and 90th centiles in parentheses)

\begin{tabular}{lll}
\hline Time of exposure & Sulphur dioxide & Fluoride \\
\hline Last 24 hours & $22 \cdot 2(1 \cdot 9-85 \cdot 3)$ & $1 \cdot 0(0 \cdot 4-3 \cdot 3)$ \\
Last 1-30 days & $32 \cdot 9(20 \cdot 9-43 \cdot 8)$ & $1 \cdot 6(0 \cdot 8-2 \cdot 8)$ \\
\hline
\end{tabular}


Table 2 Mean eosinophils, the prevalence of BHR, and some covariates in different exposure categories during the last 24 hours in the index area (Ardal) and the reference area (Lardal)

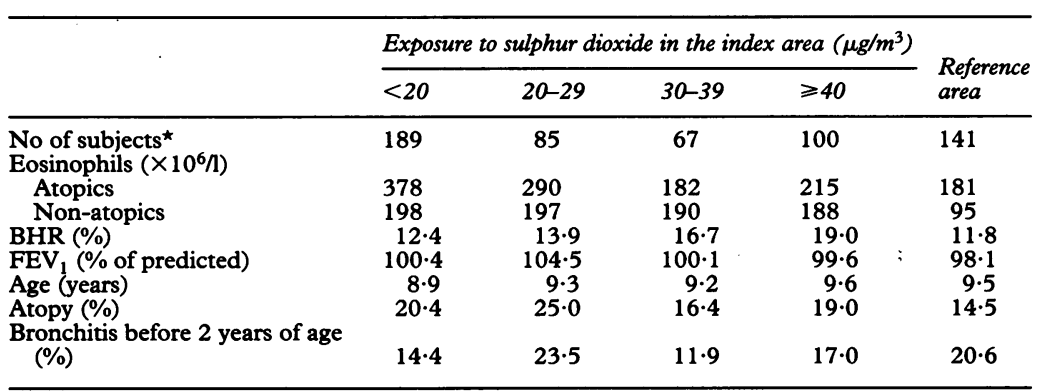

^Exposure to 38 subjects in the index group were missing.

regression model. ${ }^{16}$ The covariates were removed from the model unless the reduced model deviated from the initial model at a significance level of $5 \%$ or the coefficients of the exposure variables changed by more than $20 \%$ compared with the full model. In these analyses, sulphur dioxide and fluoride exposure data were used as continuous variables. The analysis of eosinophils was performed using the SYSTAT statistical package, ${ }^{18}$ whereas the LOGIT module of SYSTAT ${ }^{19}$ was used for the logistic regression analysis of BHR. The fit of the model was assessed using the Hosmer-Lemeshow test. ${ }^{20}$

\section{Results}

The univariate analyses indicated that the number of blood eosinophils was higher in subjects living in Årdal $\left(220 \times 10^{6} / 1\right)$ compared with those living in Lærdal $\left(106 \times 10^{6} / 1\right)$ $(p<0.001)$, at the time of the examination. The prevalence of BHR in the index area was $15.9 \%$ compared with $11.8 \%$ in the reference area $(p=0 \cdot 27)$.

The relation between eosinophils and exposure to sulphur dioxide during the last 24 hours before the examination are shown in table 2. A negative dose response relation between eosinophils and exposure to sulphur dioxide (table 2) and fluoride during the last 24 hours was indicated. A dose response relation between the prevalence of BHR and exposure to these pollutants during the last 24 hours was indicated (table 2).

The remaining analyses of the association between the outcome variables and exposure variables were restricted to the subjects in the index area using multivariate methods. These analyses were performed using indices of

Table 3 Mean (SE) change in the number of eosinophils (as $\times 10^{6} /$ ) in relation to sulphur dioxide and fluoride exposure, adjusted for atopy, obtained by multiple regression

\begin{tabular}{lll}
\hline $\begin{array}{l}\text { Time lag between } \\
\text { examination and } \\
\text { exposure }\end{array}$ & \multicolumn{2}{l}{ Exposure variable } \\
\cline { 2 - 3 } & Sulphur dioxide† & Fluoride \\
\hline Last $1-30$ days & $16(7)^{\star}$ & $26(11)$ \\
Current & $-4(3)$ & $-13(7)^{\star}$ \\
Atopy & $129(29)^{\star \star \star}$ & $121(29)^{\star \star \star}$ \\
Atopy $\times$ current & $-17(7)^{\star}$ & $-28(17)$ \\
\hline
\end{tabular}

tThe change in eosinophils by increasing sulphur dioxide exposure by $10 \mu \mathrm{g} / \mathrm{m}^{3}$. Both covariates were entered as exposure by $10 \mu \mathrm{g} / \mathrm{m}$ continuous variables.
$\star \mathrm{p}<0 \cdot 05,{ }^{\star \star} \mathrm{p}<0 \cdot 001$. sulphur dioxide and fluoride in separate models (tables 3 and 4). Regarding the analysis of eosinophils as the dependent variable atopy remained in the final model in addition to the exposure variables. Using these exposure variables as continuous covariates, a significant positive association between eosinophils and sulphur dioxide and fluoride exposure during the last 30 days before the examination was found (table 3). After inclusion of atopy and exposure during the last 30 days, the product term between atopy and exposure during the last 24 hours to sulphur dioxide was significant (table 3); that is, the association between eosinophils and exposure was restricted to the atopics. The association between eosinophils and the exposures during the last 24 hours were therefore performed in atopic and nonatopic subjects separately. In atopic subjects, increasing sulphur dioxide with $10 \mu \mathrm{g} / \mathrm{m}^{3}$ and fluoride with $1 \mu \mathrm{g} / \mathrm{m}^{3}$ was associated with a decrease in eosinophils of $-21 \times 10^{6} / 1(95 \% \mathrm{CI}$ -36 to -6$)$ and $-52 \times 10^{6} / 1(95 \%$ CI -98 to -8 ), respectively.

In accordance with the criteria of model reduction, atopy, bronchitis before 2 years of age, age, and lung function were included as covariates in the final logistic model of BHR, that is, exposure to environmental tobacco smoke was deleted during the backward elimination of the model. In the first step the relation between the prevalence of BHR and sulphur dioxide and fluoride was investigated separately (table 4). A positive relation was found between the prevalence of BHR and exposure to sulphur dioxide and fluoride during the last 24 hours, whereas no association with previous exposure was found. The product term between exposure during the last 24 hours and atopic status was not significant; that is, there was no difference between atopic and non-atopic subjects. The HosmerLemeshow test of the models showed no significant deviation between the observed and expected numbers $(p=0.67-0.99)$.

Multiple regression of the log transformed dose response slope revealed a significant associated with fluoride exposure $(p=0.003)$, but not with sulphur dioxide exposure $(\mathrm{p}=0 \cdot 17)$. The $R^{2}$ for the former model was $9 \cdot 2 \%$ and $5 \cdot 3 \%$ for the latter model.

There was a significant positive association between the prevalence of BHR and atopy (odds ratio (OR) $2 \cdot 7,95 \% \mathrm{CI} 1.4$ to $5 \cdot 5$ ) and bronchitis before 2 years of age (OR $2 \cdot 3,95 \%$ CI $1 \cdot 1$ to $4 \cdot 7$ ). The prevalence of BHR was negatively correlated to $\mathrm{FEV}_{1}$ as $\%$ of predicted (OR 0.7 by increasing $\mathrm{FEV}_{1}$ with $5 \%, 95 \% \mathrm{CI}$ 0.6 to 0.8 ) and age (OR 0.6 by increasing age with 2 years, $95 \%$ CI 0.4 to 0.9 ).

Table 4 OR (95\% CI) of BHR by increasing sulphur dioxide by $10 \mu \mathrm{g} / \mathrm{m}^{3}$ and fluoride by $1 \mu \mathrm{g} / \mathrm{m}^{3}$, adjusted for age, atopy, bronchitis before 2 years of age and lung function, obtained by logistic regression

\begin{tabular}{lll}
\hline $\begin{array}{l}\text { Time lag between } \\
\text { examination and } \\
\text { exposure }\end{array}$ & Exposure variable \\
\cline { 2 - 3 } & Sulphur dioxide & Fluoride \\
\hline Last 24 hours & $1.12(1.01$ to 1.24$)$ & $1.31(1.07$ to 1.60$)$ \\
Last $1-30$ days & $0.94(0.73$ to 1.21$)$ & $0.97(0.86$ to 1.08$)$
\end{tabular}




\section{Discussion}

We have found that exposure to sulphur dioxide and fluoride during the last 24 hours is associated with a decrease in the blood eosinophils in atopic subjects and an increase in the prevalence of BHR, the latter relation being independent of the atopic status.

The results from the Hosmer-Lemeshow test showed that the logistic regression seemed to fit the data quite well. ${ }^{16}$ On the other hand, the multiple linear regression could only explain $5-9 \%$ of the variance, indicating that the use of the logistic models were more appropriate than the linear regression models. The logistic regression revealed a significant association between BHR and both indices of exposure.

The difference in eosinophils and bronchial responsiveness between the subjects living in the index area and the reference area could be due to differences between populations. This explanation is, however, unlikely. Firstly, an association between eosinophils and bronchial responsiveness and environmental exposure was found in subjects living in the index area. Moreover, the prevalence of BHR in subjects with the lowest exposure during the last 24 hours was very close to the prevalence of BHR in the reference group. The possibility that systematic differences between the subjects within the index group could explain these findings appears unlikely. In fact, the inclusion of several potential confounders did not dilute the associations.

Furthermore, the relation between bronchial responsiveness and exposure to air pollutants appears to be influenced by the time lag between the exposure and the effect. We found that exposure during the first three years of life in these children increased the prevalence of BHR at school age. ${ }^{8}$ On the other hand, the exposure during the last 24 hours, but not during the last month, appeared to increase bronchial responsiveness. It therefore seems likely that exposure to air pollutants in infancy has a long term effect on bronchial responsiveness, whereas exposure during the last 24 hours in school age exert a short term effect which is transient.

It has been suggested that epithelial damage leads to inflammatory changes that are accompanied with BHR. ${ }^{2122}$ The bronchial responsiveness appears to be related to the numbers of eosinophils and mast cells in the bronchoalveolar fluid of asthmatics. ${ }^{23}$ Furthermore, it is hypothesised that air pollution induces epithelial damage resulting in mediator release and BHR. ${ }^{24}$ The finding that exposure to sulphur dioxide and fluoride during the last 24 hours was associated with increased prevalence of $B H R$, indicate that these irritants may induced mucosal changes leading to BHR. It appears that this response to the exposure has the same magnitude in atopic as nonatopic subjects. Our results indicate, however, that the eosinophils in atopic subjects react differently from non-atopics to irritant exposure. One may speculate if changes in the respiratory tree is associated with BHR trigger eosinophils in atopic subjects to migrate to the airways.
A positive relationship between eosinophils and 30 day exposure was found. Similar associations have, actually, been found using experimental designs. ${ }^{325}$ In these studies the number of blood eosinophils increased on the next day after allergen exposure compared with the day of the exposure. The authors suggest that the exposure stimulate the recruitment of eosinophils from the bone marrow to the blood. It is possible that exposure to air pollution for several day may have a similar effect. The analyses indicated that the strength of association to sulphur dioxide and fluoride was different in terms of bronchial responsiveness and eosinophils. Firstly, these exposure variables were highly correlated; that is, the analyses do not differentiate adequately between these two covariates. Secondly, both sulphur dioxide and fluoride might merely be indices of some other agent which is correlated to them.

The relation between peripheral eosinophils and environmental exposure to non-allergens has been investigated in only a few studies in humans. An increase in the number of blood eosinophils was found in adult smokers compared with non-smoking French policemen ${ }^{26}$ and in the male offspring of smoking parents. ${ }^{27}$ The positive association between peripheral eosinophils and environmental exposure in this study is in agreement with the first of these studies.

The relation between outdoor exposure to pollutants and respiratory symptoms, BHR, and atopy has been studied in polluted areas in Eastern Europe with less polluted areas in the West. ${ }^{28-30}$ In these studies, the prevalence of atopy ${ }^{28-30}$ and $\mathrm{BHR}^{28}$ was higher in the West than in the East although the former area was most polluted. In one of these studies, ${ }^{29}$ domestic crowding appeared to protect against atopic sensitisation. After adjustment for atopy, these differences decreased, ${ }^{28} 29$ indicating that the Western lifestyle is an independent risk factor for sensitisation that explain an increased prevalence of asthma and BHR. In our study, however, the comparisons were made between different exposure groups living in the index area. Furthermore, adjustment for atopy was included in the analyses. It thus seems likely that air pollution may increase bronchial responsiveness when other extraneous factors are taken into account.

In summary, high exposure to irritants like sulphur dioxide and fluoride during the last 24 hours is associated with an increase in bronchial responsiveness. In atopic subjects this increase in bronchial responsiveness is associated with a decrease in the peripheral eosinophils cell count. Exposure during the last month is associated with a raised number of blood eosinophils.

The authors thank Dr Dagfinn Haarr, MD, and Dr Ole Strand, $M D$, for their assistance with the performance of the study and comments on the manuscript. They are also grateful to Odd $O$ Aalen, Professor in Medical Statistics, for his statistical support. Finally, they thank Jeanette Kliger for her linguistic help.

The study was supported by grants from the Norwegian Aluminium Industry's research program of environmental effects ('The Effect Study'), the Norwegian Research Council, Årdal Municipality, the Norwegian Asthma and Allergy Association, and Lillemor Krai's legacy. 
1 Kay AB. Asthma and inflammation. $\mathcal{f}$ Allergy Clin Immunol 1991; 87: 893-910.

2 De Monchy JG, Kauffman HF, Venge $P$, et al. Bronchoalveolar eosinophils during allergen-induced late asthmatic reaction. Am Rev Respir Dis 1985; 131: 373-6.

3 Cookson WOCM, Craddock CF, Benson MK, Durham SR. Falls in peripheral eosinophil counts parallel the late asthmatic

$$
\text { 458-62. }
$$

4 Fergusson AC, Wong FWM. Bronchial responsiveness in asthmatic children. Chest 1989; 96: 988-91.

5 Tan WC, Bethel RA. The effect of platelet activating factor antagonist on ozone-induced airway inflammation and antagonist on ozone-induced airway inflammation and bronchial hyperresponsivenes
Respir Dis 1992; 146: 916-22.

6 Ohashi Y, Nakai Y, Sugiura Y, Ohno Y, Okamoto H. Nitrogen dioxide-induced eosinophilia and mucosal injury in the trachea of the guinea pig. Fournal of Otorhinolaryngology and Related Specialties 1993; 55: 36-40.

7 Lebowitz MD. Methods to assess respiratory effects of complex mixtures. Environ Health Perspect 1991; 95: 75-80

8 Søyseth V, Kongerud J, Haarr D, Strand O, Bolle R, Boe J. Relation of exposure to airways irritants in infancy to prevalence of bronchial hyper-responsiveness in schoolchildren. Lancet 1995; 345: 217-20.

9 Steen-Johnsen J, Benan K, Tolefsen E, Gonsholt G. Asthma in schoolchildren (7-13 years) in Telemark County [in Norwegian]. Norwegian fournal of Epidemiology 1993; 3: 44-6.

10 Dacie JV. Eosinophil counts by counting chamber method. Practical haematology. 6th Ed. Edinburgh: Livingstone, 1984: 42-3.

11 Belin L, Dreborg S, Einarson R, et al. Phazet $(8)$ a new type of skin prick test. Calibration and stability. Allergy 1985; 40 (suppl 4): 60-3.

12 Cotes JE. Lung function. Assessment and application in medicine. 4th Ed. Oxford: Blackwell Scientific Publications, 1979: 340.

13 Cockcroft DW, Killian DN, Mellon JA, Hargreave FE. Bronchial reactivity to inhaled histamine: a method and a clinical survey. Clin Allergy 1977; 7: 235-43.

14 Kongerud J, Søyseth V. Methacholine responsiveness, respiratory symptoms and pulmonary function in aluminium potroom workers. Eur Respir f 1991; 4: 159-66.

15 O'Connor G, Sparrow D, Taylor D, Segal M, Weiss S.
Analysis of dose-response curves to methacholine. Am Rev Respir Dis 1987; 136: 1412-7.

16 Hosmer DW, Lemeshow S. Applied logistic regression. New York: John Wiley, 1989

17 Kleinbaum DG, Kupper LL, Muller KE. Applied regression analysis and other multivariable methods. 2nd Ed. Boston: PWS-KENT Publishing Company, 1987: 316-37.

18 Wilkinson L. SYSTAT: the system for statistics. Evanston, IL. SYSTAT, 1990.

19 Steinberg D, Colla P. LOGIT: a supplementary module for SYSTAT. Evanston, IL: SYSTAT, 1991.

20 Lemeshow S, Hosmer DW. The use of goodness-of-fit statistics in the development of logistic regression models. Am $\mathcal{J}$ Epidemiol 1982; 115: 92-106.

21 O'Byrne PM. Airway inflammation and airway hyperresponsiveness. Chest 1986; 90: 575-7.

22 Rogers DF, O'Connor BJ, eds. Airway hyperresponsiveness: relation to asthma and inflammation. Thorax 1993; 48: $1095-6$.

23 Wardlaw AJ, Dannette S, Gleich GJ, Collins JV, Kay AB. Eosinophils and mast cells in bronchoalveolar lavage in subjects with mild asthma: relationship to bronchial hyperreactivity. Am Rev Respir Dis 1988; 137: 62-9.

24 Davies RJ, Devalia JL. Air pollution and airway epithelial cells. Agents Actions 1993; 43: 87-96.

25 Durham SR, Kay AB. Eosinophils, bronchial hyperreactivity and late-phase asthmatic reactions. Clin Allergy 1985; 15 : 411-8.

26 Kauffmann F, Neukirch F, Korobaeff M, Marne M-J, Claude J-R, Lellouch J. Eosinophils, smoking, and lung Claude J-R, Lellouch J. Eosinophils, smoking,
function. Am Rev Respir Dis 1986; 134: 1172-5.

27 Ronchetti R, Macri F, Ciofetta G, et al. Increased serum IgE and increased prevalence of eosinophilia in 9-year-old children of smoking parents. $\mathcal{F}$ Allergy Clin Immunol 1990; 86: 400-7.

28 von Mutius E, Martinez D, Fritzsch C, Nicolai T, Roell G, Thiemann HH. Prevalence of asthma and atopy in two areas of West and East Germany. American fournal of Respiratory and Critical Care Medicine 1994; 149: 358-64.

29 Bråbäck L, Breborowicz A, Julge $\mathrm{K}$, et al. Risk factors for respiratory symptoms and atopic sensitization in the Baltic area. Arch Dis Child 1995; 72: 487-93.

30 Bråbäck L, Breborowicz A, Dreborg S, Knutsson A, Pieklik H, Björkstén B. Atopic sensitization and respiratory symptoms among Polish and Swedish school children. Clin Exp Allergy 1994; 24: 826-35. 